J. Lake Sci.(湖泊科学), 2018, 30(1): 199-210

DOI 10. 18307/2018. 0120

(c) 2018 by Journal of Lake Sciences

\title{
鄱阳湖水龄季节性变化特征”
}

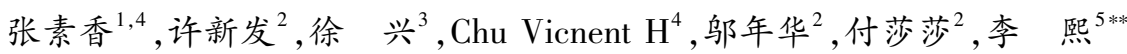

( 1 : 南京信息工程大学气象灾害教育部重点实验室,南京 210044)

(2:江西省水利科学研究院,南昌 330029$)$

(3: 江苏省水文水资源勘测局无锡分局,无锡 214031)

(4:McGill University, Department of Civil Engineering and Applied Mechanics, Montreal, Quebec H3A 2K6, Canada)

( 5 :河海大学港口海岸与近海工程学院,南京 210098)

摘 要: 基于环境水动力学模型 EFDC 源程序,建立了染色剂模型和水龄模型, 在将模型与航测水文数据验证吻合的基 础上,分别计算了鄱阳湖自然条件下春、夏、秋、冬季的水龄和倒灌前后鄱阳湖染色剂和水龄分布的变化, 以及五河水系 各分支河流水龄. 分季节的水龄计算表明鄱阳湖水体交换受季节性来水影响明显. 夏、秋季的水龄相对较小,在多数年份 又受到长江水倒灌的影响导致水龄有所增大; 冬、春季水龄较大, 亦无长江水倒灌现象, 相较于夏、秋季, 水域面积明显减 少. 分支流的水龄计算表明,西南湖区的水体交换主要受到赣江的影响,西北湖区水体交换主要受到修水和赣江的影响, 南部湖区主要受到抗河与信江的影响, 东部湖区主要受到饶河的影响,湖心区和人江水道则受到五河水系的综合影响. 同时水龄的研究表明拟建的鄱阳湖水利枢纽工程 “调枯不调洪” 的原则是合理的, 为鄱阳湖水利枢纽工程论证提供了重 要的参考依据.

关键词: 鄱阳湖; 鄱阳湖水利枢纽工程; EFDC; 风场;染色剂;水龄; 季节性变化

\section{Seasonal variations of water age in Lake Poyang}

ZHANG Suxiang ${ }^{1,4}$, XU Xinfa ${ }^{2}$, XU Xing ${ }^{3}$, CHU Vicnent $\mathrm{H}^{4}$, WU Nianhua ${ }^{2}$, FU Shasha ${ }^{2} \& \mathrm{LI} \mathrm{Xi}^{5 * *}$

(1: Key Laboratory of Meteorological Disaster of Ministry of Education, Nanjing University of Information Science \& Technology, Nanjing 210044, P.R.China)

(2: Jiangxi Provincial Research Institute of Water Science, Nanchang 330029, P.R. China)

(3: Wuxi Branch of Jiangsu Province Hydrology and Water Resource Investigation Bureau, Wuxi 214031, P.R. China)

(4: Department of Civil Engineering and Applied Mechanics, McGill University, Montreal, Quebec H3A 2K6, Canada)

(5: College of Harbor, Coastal and Offshore Engineering, Hohai University, Nanjing 210098, P.R.China)

Abstract: Based on source code of Environmental Fluid Dynamics Model (EFDC), the water age model and conservative dye model were set up to study water age of seasons and individual rivers of Lake Poyang under natural conditions. Water age calculations indicate that seasonal variations of water age in Lake Poyang are significant. The water age of summer or autumn is smaller, which is increased during reversing process in flood season in most of consecutive years. The water age of winter or spring is larger without occurrence of reversing process. The water age of individual river in five river systems indicates that the exchange of water in the southwest lake zone is mainly influenced by Ganjiang River, whereas in the northwest zone influenced by Ganjiang River and Xinjiang River, in the southern lake zone by Ganjiang River and Xinjiang River, in the eastern lake zone by Raohe River, respectively. The central zone and channel to Yangtze River are influenced by the five rivers together. The proposed Lake Poyang Complex will be rational with principles “water level control during dry seasons not during flood seasons”, and the model is proved of reference value for feasibility study of Lake Poyang Complex.

* 国家自然科学基金项目(51369011)、江西省水利科技项目 (KT201405) 和江苏省水利科技项目 (2017039) 联合资 助. 2017-03-23 收稿; 2017-05-22 收修改稿. 张素香( 1971 ), 女, 讲师, 博士; E-mail: zhangsuxiang@ nuist. edu.cn.

** 通信作者; E-mail: xili@ hhu.edu.cn. 
Keywords: Lake Poyang; Lake Poyang Complex; Environmental Fluid Dynamics Model (EFDC) ; wind; dye; water age; seasonal variation

对于水体输运时间尺度, 不同学者使用不同的模型和定义来计算分析. Deleersnijder 等 ${ }^{[1]}$ 介绍了基于对 流一扩散输运方程的水龄理论, 提供了定量地研究保守染色剂输运特征的理论和方法. Shen 等 ${ }^{[2]}$ 运用 CH3D 模型 (Chesapeake Bay model in 3 Dimensions) 来研究 Chesapeake 湾的水龄,结果表明,密度流使得水体更易向 下游运动,水体的垂直和侧向混合作用则会减弱密度流. Shen 等 ${ }^{[3]}$ 基于 FVCOM 模型, 研究了径流量、风场 和地表热通量对大伙房水库水龄和停留时间的影响, 并将滞留时间和水龄进行了对比分析. $\mathrm{Li}^{\text {等 }}{ }^{[4]}$ 选取了 国内外常用的水动力模型 (EFDC) 和典型的浅水湖泊 (太湖), 以水龄作为指标, 利用三维数值模型来衡量从 长江调水到太湖产生的稀释和转移污染物的效果. 龚然等 ${ }^{[5]}$ 利用 EFDC 模型对天印湖的水动力进行了模 拟, 计算结果显示, 天印湖的水龄主要随降水量和径流量的改变而改变,降雨量和径流量越大, 水龄越小, 而 风场作用对水龄的影响非常小. Ribbe 等 ${ }^{[6]}$ 使用 COHERENS 模型来研究 Hervey 湾的水体更新速率, 研究结 果显示, Hervey 湾内 $85 \%$ 的水体可以在 $50 \sim 80 \mathrm{~d}$ 内完成更新. Huang 等 ${ }^{[7]}$ 使用淡水留分法研究了流量对 Apalachicola 湾水体停留时间的影响, 结果表明, 当径流量从 $177 \mathrm{~m}^{3} / \mathrm{s}$ 增大到 $4561 \mathrm{~m}^{3} / \mathrm{s}$ 时, 停留时间从 $10 \mathrm{~d}$ 降到 $3 \mathrm{~d}$, 这表示增大流量将会导致停留时间减少. Kennedy 等 ${ }^{[8]}$ 基于 FLUENT 软件, 利用粒子跟踪法计算曼 彻斯特 Wachusett 水库水体平均停留时间为 $3 \sim 4 \mathrm{~d}$. Dabrowski 等 ${ }^{[9]}$ 使用 ECOMSED 模型计算爱尔兰海水体 停留时间和空间滞留时间, 结果表明,一些地区的冬季平均停留时间比夏季高出 $28 \%$. 综合以上分析, 水龄 主要用于水体内部物质交换与传输时间的计算, 反映保守染色剂的动态时间变化; 滞留时间主要用于反映 系统内水团流出前在系统内的停留时间; 而更替周期则用于描述封闭水体与外界交换的总体时间特征. 鄱 阳湖作为典型过水型浅水湖泊, 其湖泊动力特征主要受五河 (修水、赣江、抚河、信江、饶河) 水系来水的影 响, 具有流速大、水域面积季节性变化剧烈的特点; 同时鄱阳湖与长江直接相连接, 依据水位变化和长江水 体发生季节性交换, 所以也具有吞吐型湖泊的特点. 因此, 针对鄱阳湖典型过水型和吞吐型浅水湖泊的特 征,研究鄱阳湖水体交换的季节性变化更适合使用水龄的计算方法.

迄今, 水龄的相关模拟研究以采用二维模型居多 ${ }^{[1-11]}$, 水龄以保守染色剂的浓度分布变化来反映, 通常 染色剂空间浓度分布具有典型的三维特征, 理论上与水流的紊动切应力呈正相关, 因此构建三维水动力模 型框架下的水龄模型是目前区域性湖泊河网水体交换和水质模拟的重要发展方向. EFDC 三维水动力模型 提供了一个高分辨率的框架性数值模型工具来研究鄱阳湖的水体交换过程, 建立并嵌人三维 EFDC 模型中 的水龄数值模型, 提供了一个健全的方法来定量研究染色剂的输运特征 ${ }^{[12]}$.

\section{1 研究区域概况}

鄱阳湖作为可以调节长江洪水的吞吐型和过水型湖泊, 其水量和水质的变化关系到鄱阳湖流域和长江 中下游地区的用水安全. 鄱阳湖地处江西省北部, 长江中下游南岸 (图 1), 以松门山为界, 分为南北两部分, 北面为人江水道 (湖口水道), 长 $40 \mathrm{~km}$; 南面为主湖体, 长 $133 \mathrm{~km}$. 因为和长江直接相连, 洪季长江水倒灌人 鄱阳湖, 使鄱阳湖有着独一无二的水动力特性. 鄱阳湖作为中国最大的淡水湖泊, 有着丰富的湿地资源, 生 物种类繁多. 然而,近年来土地利用、水资源开发利用以及气候变暖使鄱阳湖盆地湿地区域面积急剧减少. 自 2000 年后, 鄱阳湖已经连续多年出现旱情, 根据水文数据监测, 鄱阳湖如今在夏季丰水期水域面积最大 可能达 $4000 \mathrm{~km}^{2}$ 以上, 到冬季枯水期却能减少到几百平方公里, 尤其是三峡水库运行后, 枯水情况日益加 剧, 因此加强鄱阳湖的治理和保护刻不容缓. 本文基于 EFDC 三维水动力模型 ${ }^{[13-16]}$, 建立染色剂模型和水龄 模型, 分别计算了春、夏、秋、冬季鄱阳湖的水龄以及倒灌前后鄱阳湖染色剂分布的变化; 基于水龄评估了鄱 阳湖的水体交换特征以及长江水倒灌对水体交换的影响; 通过水龄模型对拟建的鄱阳湖枢纽工程 “调枯不 调洪” 的运行原则进行研究和评价.

\section{2 鄱阳湖水龄数值模型设置}

\section{1 计算方案}

由于鄱阳湖在洪季和枯季表现出不同的水动力特性, 因此本文在计算水龄时采用分季节计算的方法, 
计算方案参见表 1 . 参照图 2, 对应方案 $1 \sim 4$, 每个季 节的起始日在鄱阳湖湖流主要人口 (修水, 赣江西、 中、南支, 抚河, 信江, 乐安河, 昌江, 饶河) 各处均持续 释放浓度为 1 (任意单位) 的示踪剂, 设置其衰减速率 为 $0 \mathrm{~d}^{-1}$; 采用 2007 年 NECP 风场 (美国国家环境预报 中心) 统计的鄱阳湖风场 (图 3); 方案 1 4 的示踪剂 标志自然条件下注人鄱阳湖的五河来水的水龄. 对应 方案 5 , 参照图 4, 为研究长江水倒灌过程对湖体水交 换的影响, 仅在湖口持续释放浓度为 1 (任意单位) 的 示踪剂, 设置其衰减速率为 $0 \mathrm{~d}^{-1}$, 此方案的示踪剂标 志倒灌进入鄱阳湖的长江水的水龄. 为分析五河水系 进人鄱阳湖的分支流水龄, 对应方案 6 , 设置了五河 水系各个河流的洪季和枯季水龄计算方案, 在洪、枯 两个季节的起始日在各水系持续释放浓度为 1 ( 任意 单位) 的示踪剂, 风场仍采用 2007 年用 NECP 风场, 此方案的示踪剂标志五河分支流的季节性水龄变化. 鉴于鄱阳湖的水域面积变化剧烈,在方案 6 中为便于 比较, 采用定义 $1 \%$ 的染色剂浓度前锋所到达湖口时 的水龄作为各河流水龄最大值.

模型在水平向采用网格数为 $185 \times 265$ 的正交曲线 网格, 其中水域计算网格有 9385 个, 网格空间步长采 用 52 655 m. 动边界的处理根据两级水深阈值采用 3 种单元: 完全湿单元适用于本单元及其相邻单元的水 深均大于预定的第二级水深阈值 (此处为 $0.05 \mathrm{~m}$ ); 完 全干单元适用于本单元水深小于预定的第一级國值

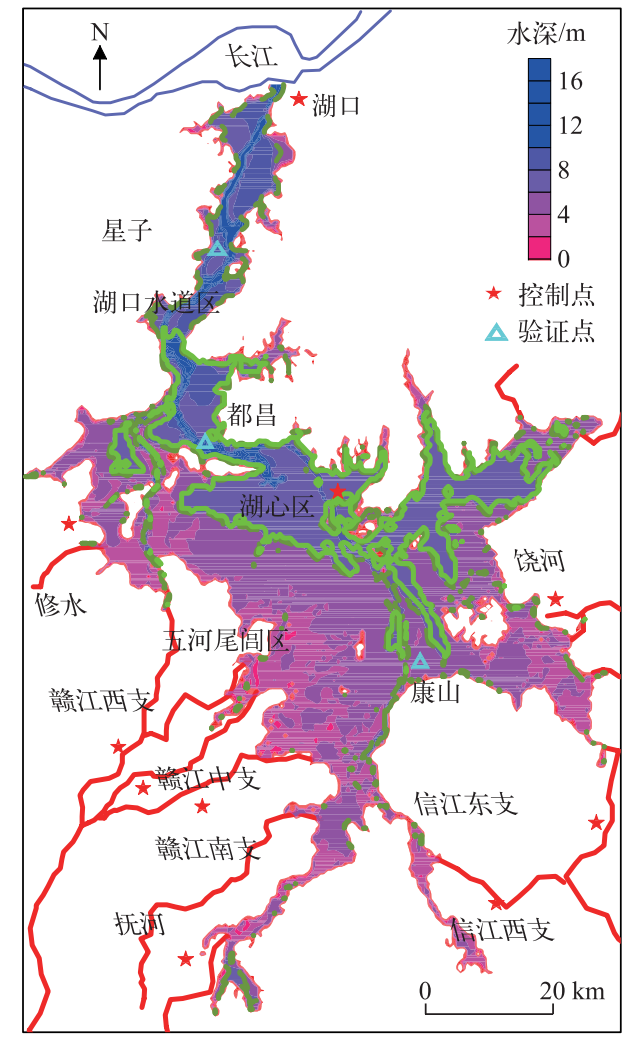

图 1 鄱阳湖地形及分区

Fig.1 Bathymetry and zones of Lake Poyang (此处为 $0.01 \mathrm{~m}$ ), 且单元所有边界均为陆地边界, 不进 行任何水力计算; 半干半湿单元适用于当本单元水深大于第一级水深阈值但小于第二级阈值, 或本单元水深 小于第一级水深國值但单元的边界不全是陆地边界, 洪水漫滩过程按照动边界处理采用半干半湿单元. 垂向 分为 4 层, 每层的厚度由湖底地形以及水面高程来决定. 模型主要受径流、表层风应力的驱动. 鄱阳湖具有浅 水湖泊的特点, 平面尺度相对较大, 因此采用垂线平均的染色剂浓度来计算水龄. 风场对鄱阳湖的湖流影响主 要是发生在南北方向上, 即与鄱阳湖水域的走向一致, 因而在季风影响上 NECP 再分析风场与实际的风场相 似. 在极端气象条件下或湖域非均匀分布风场情况下, 实际风场与 NECP 风场是有差异的,产生差异的主要原 因是 NECP 是再分析风场资料且网格尺度偏大. 考虑到基于 2007 年 NECP 风场资料风场对湖流流速的贡献在 $0.1 \mathrm{~m} / \mathrm{s}$ 以内, 此外受到缺乏实测资料的限制, 这种与实际风场的差异及修正不在本文的研究范围之内.

表 1 计算方案

Tab.1 Calculations setup

\begin{tabular}{|c|c|c|c|}
\hline 方案 & 流量 & 风场 & 季节 \\
\hline 1 & 五河+湖口 & NCEP 再分析风场 & 春 $(3$ 月 2 日 -6 月 1 日) \\
\hline 2 & 五河+湖口 & & 夏 $(6$ 月 2 日 -9 月 1 日) \\
\hline 3 & 五河+湖口 & & 秋 (9月 2 日 -12 月 1 日) \\
\hline 4 & 五河+湖口 & & 冬( 12 月 2 日至次年 3 月 1 日) \\
\hline 5 & 五河+湖口, 倒灌 & & 洪季(4-9月) \\
\hline 6 & 五河分支流的水龄 & & 洪季 ( $4-9$ 月)、枯季 ( $10-3$ 月) \\
\hline
\end{tabular}




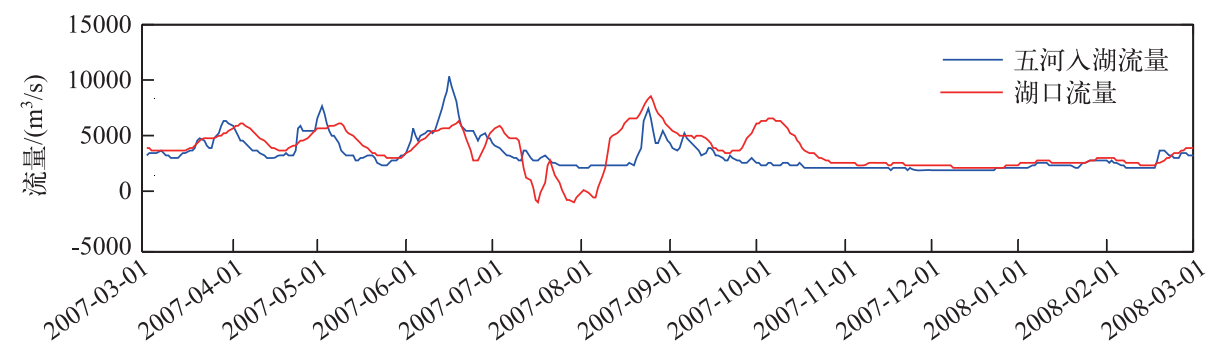

图 2 实测五河入湖流量及出湖流量 (2007 春季至 2008 年春季,倒灌为负值)

Fig. 2 Measured discharge into and out of the lake (from spring of 2007 to spring of 2008 , the reverse flow is negative)

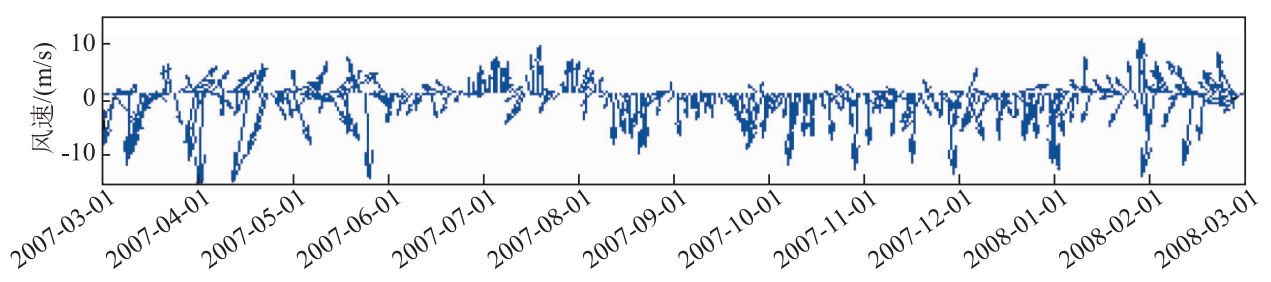

图 32007 年 3 月- 2008 年 3 月鄱阳湖 NCEP 风场资料

Fig.3 Diagram of wind velocity vector above Lake Poyang from March of 2007 to March of 2008

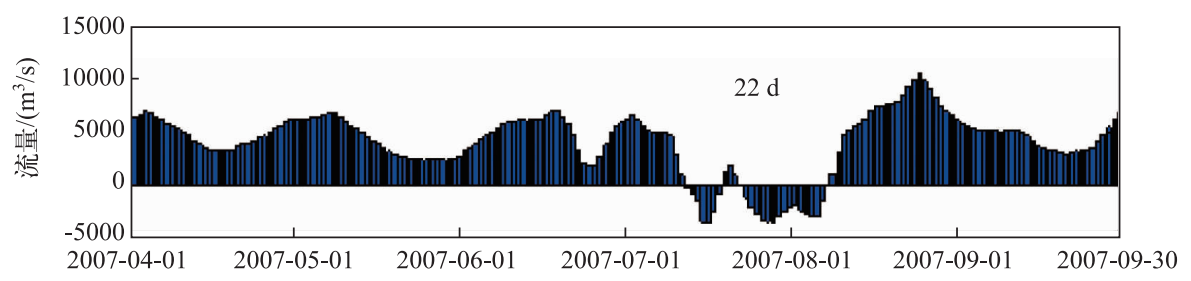

图 4 实测洪季出湖流量 (2007 年湖口日流量, 倒灌为负值)

Fig.4 Measured discharge during flood season (Hukou daily discharge in 2007, the reverse flow is negative)

\section{2 数值模型的率定和验证}

采用星子站水位和流速对模型进行精度的验证, 因缺乏全年的同步水位流速实测资料, 水位验证采用 了 2007 春季至 2008 年春季的水位资料. 江西省鄱阳湖水文局于 2011 年 11 月 13-18 日和 2012 年 5 月 $11-$ 14 日以及 $22-24$ 日在鄱阳湖和长江实施了 3 个航次的水文测验 ${ }^{[17]}$, 为模型的流速验证提供了可靠的数据. 进行水位和流速验证前, 通常需要调节底部粗粘厚度 $\left(Z_{0}\right)$. 因此对底部粗粘厚度进行了敏感性分析与测试, 选定 $Z_{0}$ 为 $0.019 \mathrm{~m}$ (通常情况下水动力模型中的设定值). 结果表明, 星子站实测水位和模型计算水位数据 吻合较好 (图 5). 对水位进行误差分析, 模型的精度由平均绝对偏差 (MAE) 和均方根误差 (RMSE) 来衡量:

$$
\begin{aligned}
M A E & =\frac{\sum\left|X_{\text {obs }}-X_{\text {sim }}\right|}{N} \\
R M S E & =\sqrt{\frac{\sum\left(X_{\text {obs }}-X_{\text {sim }}\right)^{2}}{N}}
\end{aligned}
$$

式中, $X_{\mathrm{obs}}$ 和 $X_{\mathrm{sim}}$ 分别为实测和模型计算的数值. 
通过 MAE 和 RMSE 可以直观地反映模型精度. 偏差最大时间出现在 4 月,其余的时间模型偏差很小, 总 的来说 MAE 和 RMSE 均小于 $0.4 \mathrm{~m}$ (相对误差小于 5\%), 表明模型的精度满足要求(表 2). 将星子站的实测 垂向流速分布和本模型分层计算的垂向流速分布做对比并进行误差分析, 可以看出计算的流速分布和实测 值吻合 (图 6); 从表 3 可以看出计算值与实测值吻合较好 (相对误差均小于 5\%). 同时不同时刻垂向流速分 布曲线的表层和底层差异不大, 表明鄱阳湖湖流具有典型的浅水湖泊特征, 因此下文以染色剂垂线平均分 布来表示三维染色剂和水龄计算结果输出.

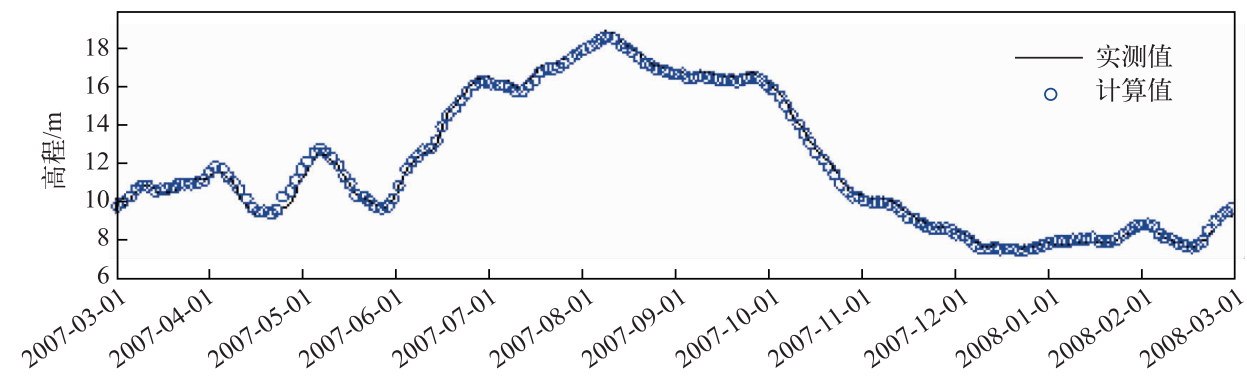

图 5 星子站水位验证(2007 春季至 2008 年春季,85 黄海基面)

Fig.5 Verification of water level in Xingzi Station

(from spring of 2007 to spring of 2008, National 85 Yellow Sea Datum)

表 2 星子站实测水位与模拟水位 $M A E$ 与 $R M S E$

Tab.2 MAE and RMSE between measured and simulated water level in Xingzi Station

\begin{tabular}{cccccccccccc}
\hline 月份 & 3 & 4 & 5 & 6 & 7 & 8 & 9 & 10 & 12 & 1 & 2 \\
\hline$M A E / \mathrm{m}$ & 0.16 & 0.30 & 0.17 & 0.12 & 0.26 & 0.22 & 0.22 & 0.17 & 0.13 & 0.15 & 0.16 \\
$R M S E / \mathrm{m}$ & 0.18 & 0.37 & 0.23 & 0.15 & 0.26 & 0.23 & 0.22 & 0.17 & 0.14 & 0.16 & 0.21 \\
\hline
\end{tabular}

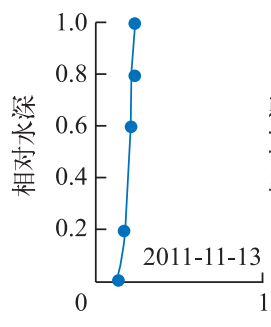

流速 $/(\mathrm{m} / \mathrm{s})$

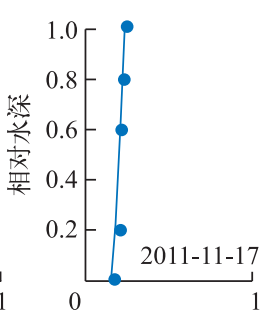

流速 $/(\mathrm{m} / \mathrm{s})$

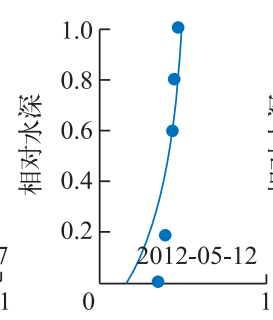

流速 $/(\mathrm{m} / \mathrm{s})$

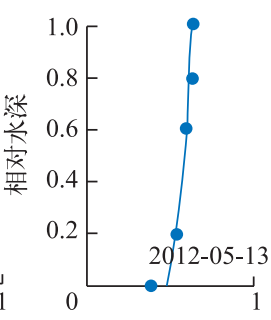

流速 $/(\mathrm{m} / \mathrm{s})$

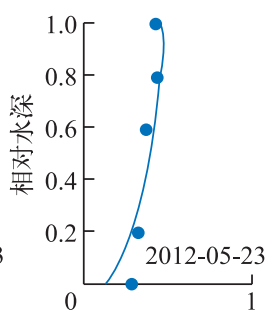

流速 $/(\mathrm{m} / \mathrm{s})$

图 6 星子站垂向流速分布验证

Fig.6 Verifications of vertical velocity distribution in Xingzi Station

\section{3 鄱阳湖水龄数值模型试验}

染色剂是指可以溶解于水中成为分子状态的着色剂, 只能以溶解态存在于水中, 通过水流来输运, 只与 水动力有关. 在湖泊研究中, 染色剂可以作为所有溶解于水且不吸附于泥沙上的物质 (比如部分污染物) 的 代称, 它通过各种物理、生物、化学过程发生衰减,其衰减的快慢通过衰减速率来确定. 染色剂模型是水龄模 型的基础, 水龄被定义为在一个复杂的水体里的时间和空间上的变量. 结合鄱阳湖的实际情况,基于环境水 动力学模型 EFDC 源程序, 建立了染色剂模型和水龄模型并纳人 EFDC 的三维水动力模型, 通过水龄的计 
表 3 星子站垂向平均流速和流向的实测值与模拟值比较

Tab.3 Comparisons between measured and simulated vertical averaged velocity and direction in Xingzi Station

\begin{tabular}{|c|c|c|c|c|}
\hline \multirow{2}{*}{ 日期 } & \multicolumn{2}{|c|}{ 流速/(m/s) } & \multicolumn{2}{|c|}{ 流向/ㅇ } \\
\hline & 实测值 & 模拟值 & 实测值 & 模拟值 \\
\hline 11 月 13 日 & 0.20 & 0.20 & 65 & 66 \\
\hline 11 月 14 日 & 0.22 & 0.22 & 74 & 75 \\
\hline 11 月 15 日 & 0.26 & 0.27 & 27 & 26 \\
\hline 11 月 16 日 & 0.23 & 0.22 & 29 & 31 \\
\hline 11 月 17 日 & 0.22 & 0.23 & 320 & 317 \\
\hline 5 月 11 日 & 0.46 & 0.45 & 20 & 19 \\
\hline 5 月 12 日 & 0.42 & 0.42 & 22 & 21 \\
\hline 5 月 13 日 & 0.58 & 0.56 & 17 & 18 \\
\hline 5 月 14 日 & 0.52 & 0.53 & 22 & 23 \\
\hline 5 月 22 日 & 0.37 & 0.37 & 328 & 330 \\
\hline 5 月 23 日 & 0.38 & 0.36 & 332 & 331 \\
\hline
\end{tabular}

算, 可以定量地评价五河水系水体的运动和交换程度以及滞留情况, 对评估鄱阳湖水体的交换以及水质的 变化具有重要意义.

\section{1 染色剂和流场的季节性分布特征}

本文采用鄱阳湖 2007 年春季至 2008 年冬季流量、水位、风场以及地形数据, 建立 EFDC 三维水动力模 型及染色剂模型. 染色剂模型建立在水动力模型的基础上, 水动力模型经过准确计算并率定分析后再建立 染色剂模型. 由模拟结果 (图 7) 可知,湖流流速的变化主要受径流影响,受风场的影响较小. 春季星子站的 流速变化范围为 $0.28 \sim 0.71 \mathrm{~m} / \mathrm{s}$; 夏季星子站的流速变化范围为 $0.40 \sim 0.78 \mathrm{~m} / \mathrm{s}$ (倒灌期间流速在 $0 \sim 0.50 \mathrm{~m} /$ s); 秋季星子站的流速变化范围为 $0.26 \sim 0.72 \mathrm{~m} / \mathrm{s}$; 冬季星子站的流速变化范围为 $0.19 \sim 0.69 \mathrm{~m} / \mathrm{s}$; 夏季的流 速变幅最小, 而秋季流速变幅最大. 湖流方向随径流的改变而变化, 染色剂从五河水系人口处放人, 随着湖 流方向开始扩散. 示踪剂的分布反映了注人鄱阳湖的五河来源的水体季节性变化, 总体上, 东北部水体交换 缓慢, 西南部水体交换迅速. 浅水湖泊的湖流常常表现为急变流 (弗劳德数大于 1), 譬如: 鄱阳湖行洪漫滩 过程或拟建枢纽工程水闸运行时的闸下出流, 急变流模拟在数值上需要解决的关键问题是控制亚网格伪物 理耗散效应. 此外, 急变流条件下染色剂的分布与缓变流有较大差别, 受到表面波的影响. 目前仍较多地依 赖物理模型试验和现场实际测量.

\section{2 鄱阳湖水龄的季节性变化}

基于染色剂模型对水龄进行计算,结果(图 8) 表明,春季出湖口的水龄为 $45 \mathrm{~d}$,夏季出湖口的水龄为 35 $\mathrm{d}$ (在东北湖湾处的水龄为 $65 \mathrm{~d}$ ), 秋季出湖口的水龄为 $27 \mathrm{~d}$, 冬季出湖口的水龄为 $52 \mathrm{~d}$. 四季出湖水龄从小 到大依次为秋季、夏季、春季、冬季, 湖心区的水龄又小于东北湖湾处的水龄. 水龄越大, 水体交换的速率越 慢. 从湖区水龄的空间分布来看, 湖心区的水龄远远小于东北湖湾处水龄, 表明自然状况下东北湖湾处水体 交换极为缓慢. 水龄分布显示了鄱阳湖过水型湖泊的特点, 鄱阳湖主湖区水体交换受季节性来水影响明显, 夏、秋季的水龄相对小, 在多数年份又受到长江倒灌的影响使水龄有所增大, 总的来说夏、秋季水循环较好 且水质由于长江水倒灌得到改善. 冬、春季鄱阳湖湖流显著减弱, 相较于夏、秋季水龄较大, 尤其是冬季水龄 最大, 表明冬季水循环在自然条件下最为缓慢且水质较差. 鄱阳湖夏季盛行偏南季风, 冬季盛行偏北季风, 其他两季存在过度期. 鄱阳湖季节性水龄变化与季风也有相关性, 在夏季偏南向季风的作用下, 南北向的水 域地形保持了较大的风区和风生流的量值, 并且风生流的方向与人湖径流方向一致, 偏南季风有减少水龄 的趋势. 与夏季偏南季风的作用相反, 在冬季偏北季风作用下风生流的方向与人湖径流方向相反, 冬季偏北 季风有增大水龄的趋势. 季风对水龄的影响与模型的计算结果相一致, 由此得出季风加剧了鄱阳湖水龄季 节性差异的结论. 相较于洪季 (4-9 月), 枯季 (10 月至次年 3 月) 的水位较低、流速小, 存在水域面积不足的 问题. 拟建的鄱阳湖大孔径水闸通过调节水位能够有效地调度湖区水量, 是改善枯季水域面积不足的有效 


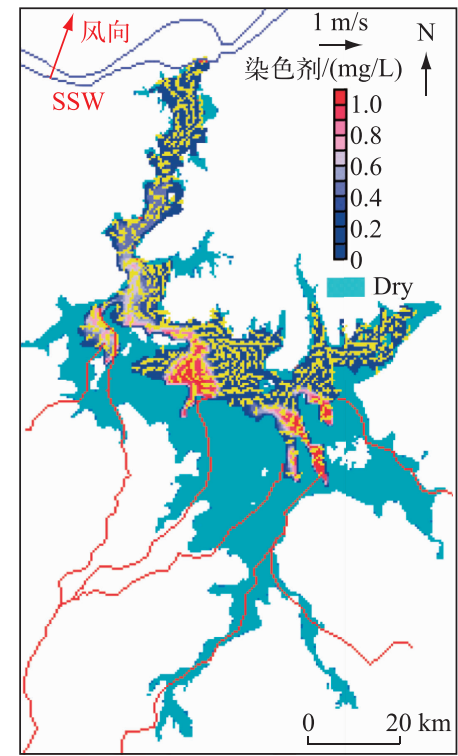

(a) 春季

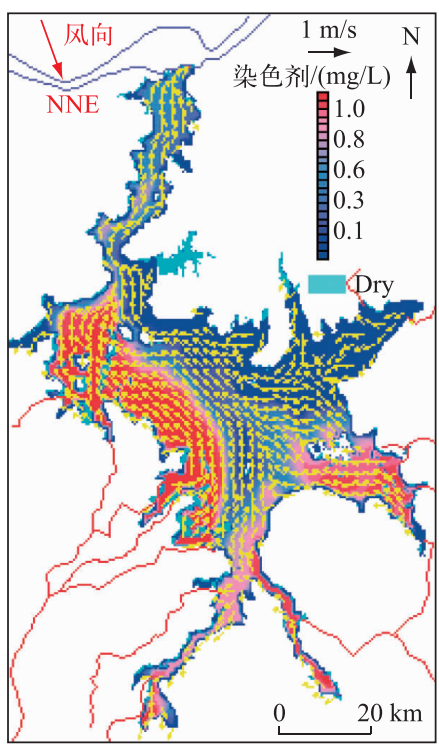

(c) 秋季

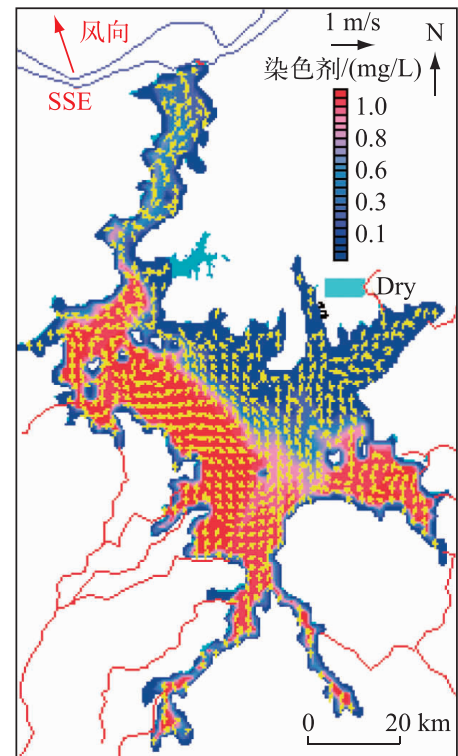

(b) 夏季

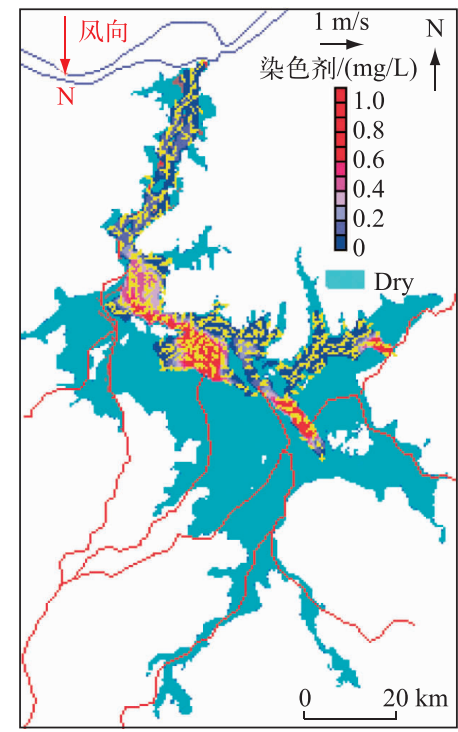

(d) 冬季

图 7 季风影响下人湖染色剂和垂向平均流速流场分布

Fig.7 Dye and averaged vertical velocity distributions under monsoon

措施. 此外, 染色剂作为标志水团来源及其运动位置的一个指标, 较为精确地反映了不同来源的水团在紊动 水流作用下的对流和扩散过程.

\section{4 长江水倒灌对鄱阳湖水龄的影响}

为研究长江水倒灌对鄱阳湖的影响 ${ }^{[18-20]}$, 不仅要关注倒灌的天数更要关注倒灌水量的大小. 在 19512007 年连续 57 个统计年中共发生倒灌 48 次, 累计率为 $50 \%$ 的倒灌水量是 25 亿 乙 $^{3}, 2007$ 年的倒灌水量是 


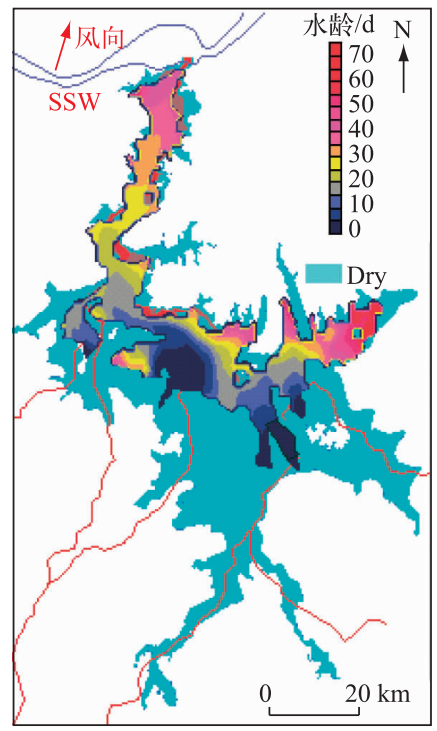

(a) 春季

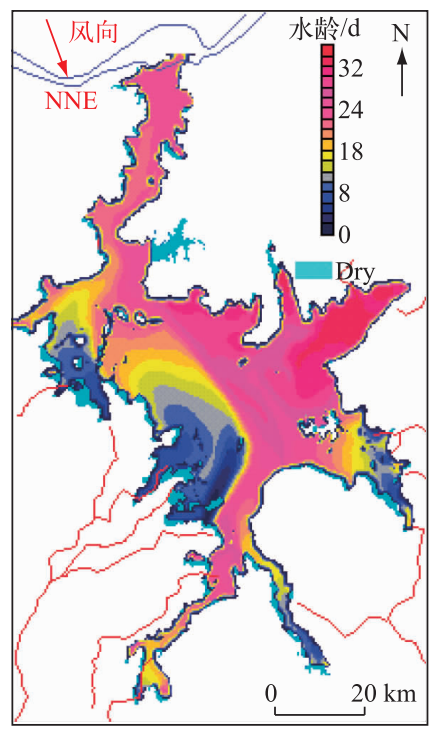

(c) 秋季

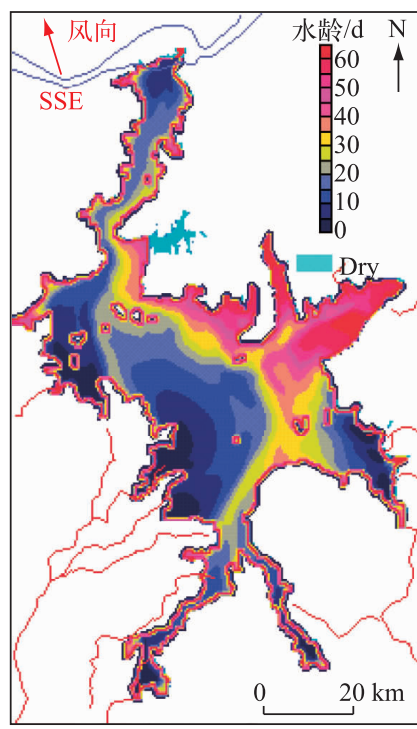

(b) 夏季

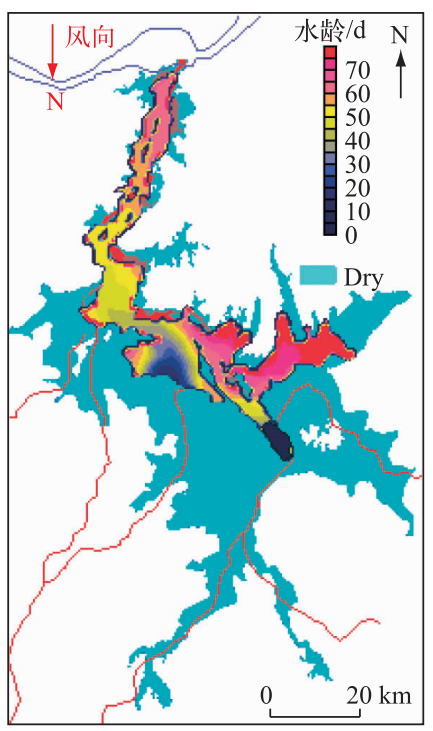

(d) 冬季

图 8 季风影响下鄱阳湖水龄的季节分布

Fig. 8 Water age distribution in Lake Poyang under monsoon

45.2 亿 $\mathrm{m}^{3}$, 处于累计率约 80\%. 典型年宜选择倒灌量中等偏大的年份, 因此以 2007 年作为典型年是合理的. 根据历年的统计分析倒灌主要发生在洪季, 但在 1974 年 10 月、1983 年 10 月和 1996 年 11 月也都发生过倒 灌, 2007 年鄱阳湖共发生两次倒灌 (表 4), 因为两次倒灌的时间相隔较近, 因此本文选取两次倒灌连续计算 模拟 ( $22 \mathrm{~d}$ ), 在湖口 (长江水进人鄱阳湖) 释放任意单位为 1 的染色剂, 染色剂不为 0 的地方即为长江水到 达的地方. 模拟结果 (图 9) 表明, 2007-2008 年的枯季, 湖流方向从南向北; 在 2007 年的汛期倒灌期间, 湖 口的湖流方向从北向南. 这个倒灌过程的模拟还原了长江对鄱阳湖的淡水补充过程, 水龄的模拟显示这种 交换对鄱阳湖水质提升很重要, 倒灌人湖的水体扩散和输运的范围越远对湖区水质的提升越有利, 还为鱼 
类迁移和生物多样性提供了一个重要通道 ${ }^{[21-23]}$. 洪季倒灌人湖的优质水能够在湖心对流扩散缓慢的区域保 持到枯季, 在鄱阳湖水利枢纽大孔闸蓄水运行的条件下,枯季的水质也能够得到提升. 因此根据水位的变化 设置拟建鄱阳湖枢纽工程的水闸 “调枯不调洪” 的调蓄原则, 对于保持鄱阳湖和长江水的水体交换和湖流变 化以及满足生物多样性需求有重要意义.

表 42007 年鄱阳湖倒灌面积

Tab.4 Reverse flow area of Lake Poyang in 2007

\begin{tabular}{lccc}
\hline 倒灌发生时间 & 倒灌的时长 $/ \mathrm{d}$ & 染色剂浓度 $>0.1 \mathrm{mg} / \mathrm{L}$ 的面积 $/ \mathrm{km}^{2}$ & 染色剂浓度 $>0.01 \mathrm{mg} / \mathrm{L}$ 的面积 $/ \mathrm{km}{ }^{2}$ \\
\hline 7 月 12 日-7 月 19 日 & 7 & 210 & 287 \\
7 月 23 日-8 月 7 日 & 15 & 325 & 432 \\
8 月 12 日(扩散面积最大) & 32 & 745 & 1031 \\
\hline
\end{tabular}

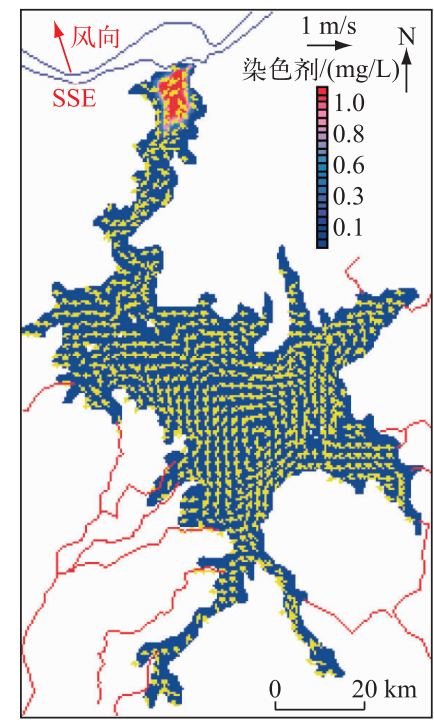

(a) 第一次倒灌末染色剂分布

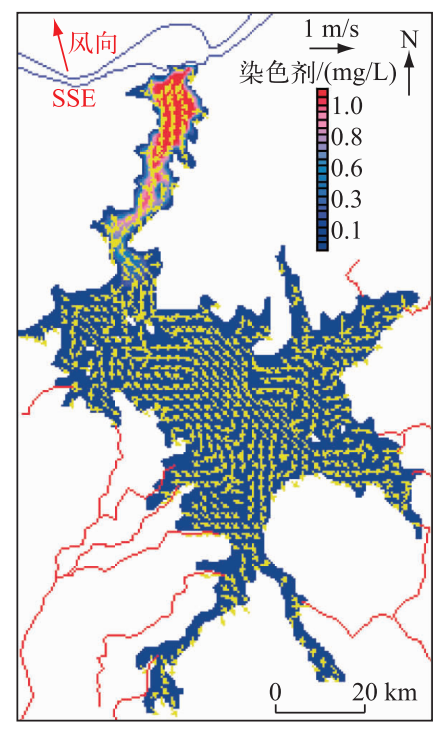

(b) 第二次倒灌末染色剂分布

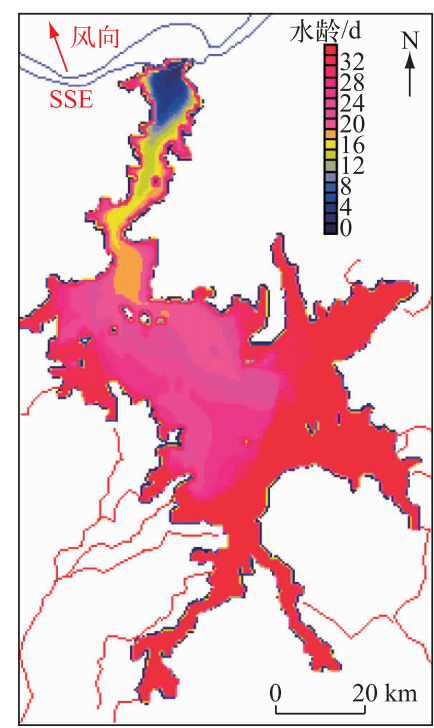

(c) 倒灌入湖的长江水龄分布

图 92007 年洪季倒灌期间流速染色剂和水龄分布

Fig.9 Distribution of velocity, dye and water age during reverse flow in flood season of 2007

\section{5 鄱阳湖五河水系各河流水龄}

为进一步分析水资源的分布, 针对各人湖河流分别进行了水龄计算, 选择适合鄱阳湖分支流水龄计算 的 $1 \%$ 浓度前锋重新定义了水龄. 各支流水龄进行计算对鄱阳湖河网与受水区水量分配和水体交换的分区 有重要意义. 修水洪季出湖口的水龄为 $32 \mathrm{~d}$, 枯季出湖口的水龄为 $55 \mathrm{~d}$; 赣江洪季出湖口的水龄为 $22 \mathrm{~d}$, 枯 季出湖口的水龄为 $51 \mathrm{~d}$; 抗河洪季出湖口的水龄为 $107 \mathrm{~d}$, 枯季出湖口的水龄为 $87 \mathrm{~d}$; 信江洪季出湖口的水龄 为 $82 \mathrm{~d}$, 枯季出湖口的水龄为 $69 \mathrm{~d}$; 饶河洪季出湖口的水龄为 $98 \mathrm{~d}$, 枯季出湖口的水龄为 $128 \mathrm{~d}$ (图 10 和图 11). 从分支流的水龄计算可知, 修水、饶河和赣江洪季水龄小于枯季水龄,而抚河、信江洪季水龄大于枯季 水龄, 表明在鄱阳湖水体交换上不同河流具有不同的特点, 这与自然条件下的观测结果也是相吻合的,因此 需要根据各支流的情况设计不同的调度运行方案. 赣江的出湖水龄在洪季和枯季都相对较小, 表明贑江的 流量在鄱阳湖水体交换过程中起主导作用. 对于西南湖区, 水龄主要受到赣江的影响; 对于西北部湖区, 水 龄受到赣江和修水的共同影响; 对于南部湖区, 受抚河和信江的影响较大; 东部湖区则受饶河的影响较大; 
湖心区和人江水道的水龄则受到五河水系的综合影响. 上述分区水龄的分析表明在人江水道选择建闸是合 理的, 各水系的水龄特征直接影响着枢纽工程水闸运行方案的制定及调度方案的具体实施, 同时为各支流 的水闸系统对湖区水资源进行预先调节提供了参考.

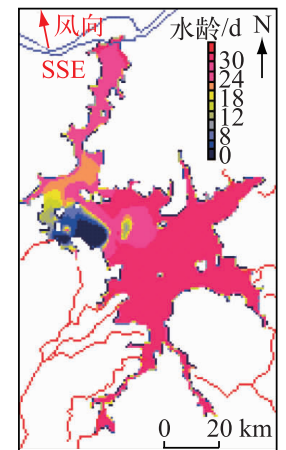

修水

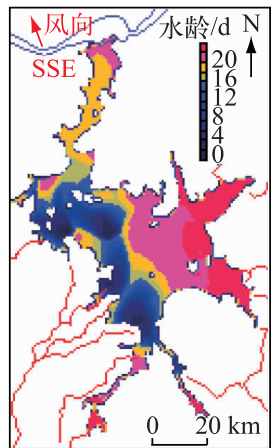

赣江

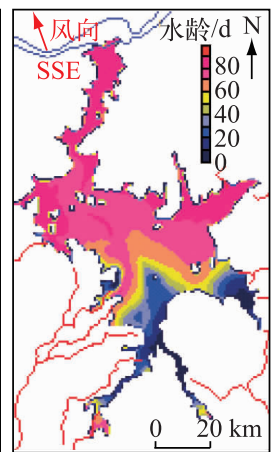

抚河

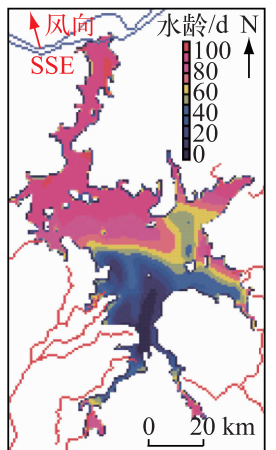

信江

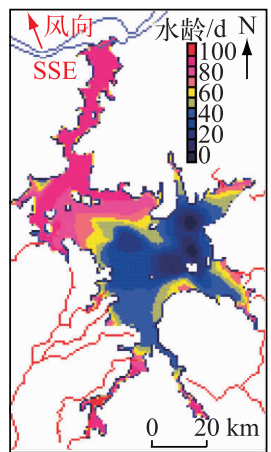

饶河

图 10 洪季各分支河流水龄分布 (2007 年 4-9 月)

Fig.10 Water age distributions of individual river in flood season (from April to September of 2007)

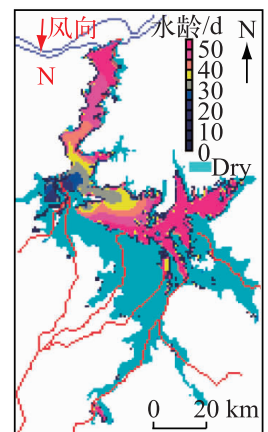

修水

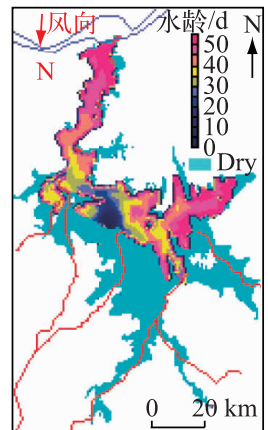

赣江

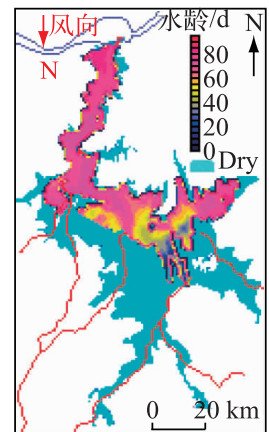

抚河

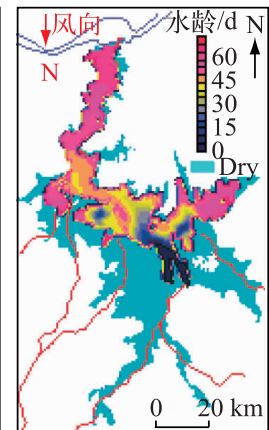

信江

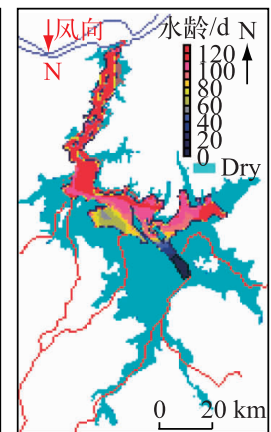

饶河

图 11 枯季各分支河流水龄分布 $(2007$ 年 10 月- 2008 年 3 月)

Fig.11 Water age distributions of individual river in dry season (from October of 2007 to March of 2008)

\section{6 结论}

本文建立了基于 EFDC 的三维水动力水龄模型来研究鄱阳湖水龄的季节性变化以及倒灌过程对其的影 响. 鄱阳湖的水龄模型既反映了来源于五河水系的径流在湖区的更新速率, 也反映了长江水倒灌人湖水体 与湖体的交换. 鄱阳湖的水体交换与更新速率主要受到季节性的流量变化影响, 风场等因素对水龄的影响 较小. 对于 2007-2008 年来源于五河水系的水体, 春季的出湖水龄约为 $45 \mathrm{~d}$, 夏季的出湖水龄约为 $35 \mathrm{~d}$, 秋 季的出湖水龄约为 $27 \mathrm{~d}$, 冬季的出湖水龄约为 $52 \mathrm{~d}$; 倒灌人湖的长江水水体的水龄约为 $32 \mathrm{~d}$, 水龄计算显示 夏、秋季的水龄小于冬、春季,表明冬、春季的水体交换速率相对缓慢,而夏、秋季水体交换速率相对较快. 通 常发生在夏、秋季的长江水倒灌过程使水龄增大, 染色剂和水龄模型结果表明长江水可以进人湖心区并在 湖区停留较长时间, 相应地鄱阳湖湖区水质也因长江水的注人而改善. 对于拟建中的鄱阳湖水利枢纽工程, 其“调枯不调洪” 的运行原则是基本符合鄱阳湖水体交换的自然规律的,能够改善湖区的枯季蓄水量和调节 湖区的水体交换. 分支流的水龄计算表明: 赣江的洪季出湖水龄最小, 对出湖水龄的主要影响来自赣江. 西 
北部湖区水体交换主要受到赣江和修水的影响;西南部湖区水体交换主要受赣江的影响;南部湖区水体交 换受抚河和信江的影响较大; 东部湖区水体交换则受饶河的影响较大;湖心区和人江水道的水体交换则受 到五河水系的综合影响. 因此, 在人江水道上建设水利枢纽工程是合理的选择, 利用人湖河流的水闸系统进 行湖区蓄水量的预调节将有利于鄱阳湖枢纽调度方案的制定和实施. 此外, 鄱阳湖水利枢纽的建设无疑会 增大枯季的水龄, 即减缓水体交换的速率, 因此选择保持一定的枯季生态流量, 在枯季选择持续的蓄水或间 断的蓄水是制定合理的枢纽工程水闸运行规则的重要方面,而水龄的计算为鄱阳湖枢纽工程的可行性研究 提供了重要的参照. 水龄的分布和保守示踪剂的浓度计算针对水团的对流一耗散过程, 同时为反应-耗散过 程提供了泥沙水质等环境变量的背景浓度场, 因此水龄的概念虽然源自水动力计算同时也是水质和生态环 境变量的重要研究基础. 实测资料的分析表明 2007 年是枯水年, 从理论发展和实际应用的角度,结合不同 水文情势分析不同代表年情景下水龄季节变化的变幅及差异也是今后的重要研究方向. 此外,结合物模试 验成果和现场观测资料, 进一步开展高分辨率的急变流模式研究, 是解决拟建鄱阳湖枢纽工程水闸运行方 式及其影响的关键,也是今后浅水湖泊湖流及水体交换混合的重要研究方向.

致谢:感谢江西省水利科学研究院的各位同仁在野外采样工作中给予的无私帮助,感谢论文完成过程中南 昌大学胡振鹏教授、江西省水利厅谭国良高工给予的宝贵建议.

\section{7 参考文献}

[ 1 ] Deleersnijder E, Campin JM, Delhez EJM. The concept of age in marine modelling I. Theory and preliminary model results. Journal of Marine Systems, 2001, 28(3/4) : 229-267.

[ 2 ] Shen J, Wang HV. Determining the age of water and long-term transport timescale of the Chesapeake Bay. Estuarine, Coastal and Shelf Science, 2007, 74(4) : 585-598.

[ 3 ] Shen YM, Wang JH, Zheng BH et al. Modeling study of residence time and water age in Dahuofang Reservoir in China. Science China-Physics, Mechanics \& Astronomy, 2011, 54(1) : 127-142.

[ 4 ] Li YP, Acharya K, Chen D et al. Modeling water ages and thermal structure of Lake Mead under changing water levels. Lake and Reservoir Management, 2011, 26(4) : 258-272.

[ 5 ] Gong R, Xu J, Xu LG et al. Study on hydrodynamics in urban landscape lake based on EFDC. Environmental Engineer$i n g, 2015$, (4) : 58-62. [ 龚然, 徐进, 徐力刚等. 基于 EFDC 城市景观湖泊水动力模拟研究. 环境工程, 2015, (4) : 58-62.]

[ 6 ] Ribbe J, Wolff JO, Staneva J et al. Assessing water renewal time scales for marine environments from three-dimensional modelling: A case study for Hervey Bay, Australia. Environmental Modelling \& Software, 2008, 23(10/11) : 1217-1228.

[ 7 ] Huang WR, Spaulding M. Modelling residence-time response to freshwater input in Apalachicola Bay, Florida, USA. Hydrological Processes, 2002, 16(15) : 3051-3064.

[ 8 ] Kennedy MG, Ahlfeld DP, Schmidt DP et al. Three dimensional modeling for estimation of hydraulic retention time in a reservoir. Journal of Environmental Engineering-ASCE, 2006, 132(9) : 976-984.

[ 9 ] Dabrowski T, Hartnett M, Olbert AI. Determination of flushing characteristics of the Irish Sea: A spatial approach. Computers \& Geosciences, 2012, 45: 250-260.

[10] Arega F, Armstrong S, Badr AW. Modeling of residence time in the East Scott Creek Estuary, South Carolina, USA. Journal of Hydro-environment Research, 2008, 2 (2) : 99-108.

[11] Shao JR, Wu SQ, Zhou J et al. An age model for water transfer. Advances in Water Science, 2014, 25(5): 695-703. [邵 军荣, 吴时强, 周杰等. 水体交换年龄模型研究. 水科学进展, 2014, 25(5) : 695-703.]

[12] Huang CL, Li X, Sun YY. Water age distribution of the Taihu Lake and impact of the Yangtze River to Taihu Lake Water Transfer Project on water age. J Lake Sci, 2017, 29 (1): 22-31. DOI:10.18307/2017.0103. [黄春琳, 李熙, 孙永远. 太湖水龄分布特征及“引江济太”工程对其的影响. 湖泊科学, 2017, 29 (1) : 22-31.]

[13] Zhang XL, Li YL, Yu G et al. Runoff simulation and response to climate changes for Poyang Basin during the past 1000 years. J Lake Sci, 2016, 28(4) : 887-898. DOI:10.18307/2016.0423. [张小琳, 李云良, 于革等. 鄱阳湖流域过去 $1000 \mathrm{a}$ 径流模拟以及对气候变化响应研究. 湖泊科学, 2016, 28(4) : 887-898.]

[14] Li X, Wang YG, Zhang SX. Numerical simulation of water quality in Yangtze Estuary. Water Science and Engineering, 
2010, $2(4): 40-42$.

[15] Zhang SX, Mei M, Xu XF et al. Numerical modeling of water level and current in very shallow lake Poyang. 12th International conference on fuzzy systems and knowledge discovery, FSKD, 2015: 2544-2548.

[16] Qi W , Li YP, Wang Y et al. Control and optimization scheme of TianJing Lake hydrodynamics based on EFDC model. Water Resources and Power, 2015, (1): 47-51. [戚文, 李一平, 王莹等. 基于 EFDC 模型的天镜湖水动力优化调控方 案研究. 水电能源科学, 2015, (1): 47-51.]

[17] Zhang C, Min Q, Cao Y et al. The hydrology report of field investigations for verifications of similarity rule in Poyang Lake physical model. Poyanghu Hydrology Bureau of Jiangxi Province, 2012. [张纯, 闵骞, 曹美等. 鄱阳湖实体模型相似验 证原型水文测验报告. 江西省鄱阳湖水文局, 2012.]

[18] Tang CX, Xiong X, Wu NH et al. Simulation of the impact of the reverse flow from Yangtze River on the hydrodynamic process of Lake Poyang. J Lake Sci, 2015, 27 (4) : 700-710. DOI:10.18307/2015.0419. [ 唐昌新, 熊雄, 鸟年华等. 长 江倒灌对鄱阳湖水动力特征影响的数值模拟. 湖泊科学, 2015, 27(4): 700-710.]

[19] Hu Q, Feng S, Guo H et al. Interactions of the Yangtze river flow and hydrologic processes of the Poyang Lake, China. Journal of Hydrology, 2007, 347 (1/2): 90-100.

[20] Guo H, Hu Q, Zhang Q et al. Effects of the Three Gorges Dam on Yangtze River flow and river interaction with Poyang Lake, China: 2003-2008. Journal of Hydrology, 2012, s416/417(2) : 19-27.

[21] Xie DM, Deng HB, Wang DY et al. Zoning of ecological function importance for Lake Poyang wetlands. J Lake Sci, 2011, 23(1) : 136-142. DOI: 10.18307/2011.0120. [谢冬明, 邓红兵, 王丹寅等. 鄱阳湖湿地生态功能重要性分区. 湖泊 科学, $2011,23(1): 136-142$. ]

[22] Zhang QJ, Yu XB, Hu BH. Research on the characteristics of plant communities in the Poyang Nanji wetlands, China. Resources Science, 2013, 35(10): 42-49. [张全军, 于秀波, 胡斌华. 鄱阳湖南矶湿地植物群落分布特征研究. 资源科 学, 2013, 35(10): 42-49.]

[23] Dong YY ed. Contingent valuation of Yangtze finless porpoisesin Poyang Lake, China. Springer, 2013. 